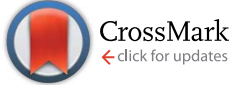

Cite this: RSC Adv., 2017, 7, 16302

Received 10th February 2017

Accepted 1st March 2017

DOI: $10.1039 / c 7 r a 01726$

rsc.li/rsc-advances

\section{Synthesis and organic field effect transistor properties of isoindigo/DPP-based polymers containing a thermolabile group $\uparrow$}

\author{
Mohamed Shaker, tab $^{\mathrm{b}}$ Byoungwook Park, + $^{\mathrm{a}}$ Jong-Hoon Lee, t $^{\mathrm{a}}$ Wonbin kim, ${ }^{\mathrm{a}}$ \\ Cuc Kim Trinh, ${ }^{a}$ Hong-Joon Lee, ${ }^{a}$ Jin woo Choi, ${ }^{a}$ Heejoo Kim, ${ }^{a}$ Kwanghee Lee*a \\ and Jae-Suk Lee*a
}

(E)-6,6' - Dibromo-1,1-bis(2-octyldodecyl)-(3,3' -biindolinylid-ene)-2,2' -dione and/or 2,5-bis(2-octyldodecyl)3,6-di(5-bromothien-2-yl)pyrrolo[3,4-c]pyrrole-1,4-(2H,5H)-dione and their tBoc-counterparts were propagated with 2,5-bis(tributylstannyl)thiophene in a molar ratio of $0.8: 0.2: 1.0$ to release P(ODIDTBID), P(ODIDT·BDPP), P(ODDPPT·BID) and P(ODDPPT·BDPP) as a new series of random conjugated polymers (RCPs) bearing a large number of octyldodecyl chains to ensure solubility and a small number of thermocleavable tBoc function to cast $\mathrm{H}$-bonding upon heating up to $220^{\circ} \mathrm{C}$. All new polymers were synthesised via Pd catalysed Stille cross-coupling methodology in high yields and reasonable average molecular weights. The cast polymer films exhibited considerable red-shifted UV-vis absorption spectra and a further red-shift was also obtained in the thermal annealed films (at $220{ }^{\circ} \mathrm{C}$ for $30 \mathrm{~min}$ ), which reflected the increasing of crystalline structure. The formation of $\mathrm{H}$-bonding in these polymers was investigated using X-ray diffractometry (XRD) measurements. The field-effect mobilities of these polymers were investigated in the configuration of bottom-gate and bottom-contact (BGBC) field-effect transistors (FETs). The results from FETs indicated that the crystalline structure of RCPs exhibited reasonable FET mobilities with $1.17 \times 10^{-3} \mathrm{~cm}^{2} \mathrm{~V}^{-1} \mathrm{~s}^{-1}$ for P(ODDPPT.BID) and $1.41 \times 10^{-3} \mathrm{~cm}^{2} \mathrm{~V}^{-1} \mathrm{~s}^{-1}$ for P(ODDPPT. BDPP).

\section{Introduction}

For the past decade, isoindigo (ID) and diketopyrrolopyrrole (DPP) based $\pi$ conjugated polymers (CPs) have attracted much attention as electronic materials for solution processing polymer solar cells (PSCs) ${ }^{\mathbf{1}, \mathbf{2}}$ and organic field-effect transistors (OFETs). ${ }^{1-3}$ As is well known, ID and DPP possess interesting properties, such as a highly fused conjugated structure, electron-deficient nature and easy synthesis. These characteristics are reflected in their polymers, which show low bandgaps, strong $\pi-\pi$ interactions, high crystallinity and high charge carrier mobility. In addition, ID and DPP based polymers have alkyl chains on their $\mathrm{N}$ atoms to induce solubility.

${ }^{a}$ School of Materials Science \& Engineering, Research Institute for Solar and Sustainable Energies (RISE), Heeger Center for Advanced Materials (HCAM), Advanced Photonics Research Institute, Gwangju Institute of Science and Technology, Gwangju 500-712, Korea. E-mail: jslee@gist.ac.kr

${ }^{b}$ Chemistry Department, Faculty of Science, Tanta University, Tanta 31527, Egypt

$\dagger$ Electronic supplementary information (ESI) available: Thermogravimetry analysis, FT-IR spectra and characterization data $\left({ }^{1} \mathrm{H}\right.$ and ${ }^{13} \mathrm{C}$ NMR spectra). See DOI: $10.1039 / \mathrm{c} 7 \mathrm{ra01726j}$

\$ Mohamed Shaker contributed equally with Byoungwook Park and Jong-Hoon Lee to this work. The manuscript was written through the contributions of all authors. All authors have given approval to the final version of the manuscript.
However, CPs based on the two units exhibit different optical and electrochemical properties, such as the highest occupied molecular orbital (HOMO), the lowest unoccupied molecular orbital (LUMO) and band gaps. To date, the donor-acceptor (DA) system, the alternative linkage between electron-rich and electron-deficient aromatic units, is one of the important protocols to design low bandgap electron donating materials in organic photovoltaic cells (OPVs), ${ }^{4}$ as well as high mobility CPs for OFETs. ${ }^{5-7}$ Careful design and the matching between the selected donor and acceptor molecular units help us to tune the HOMO and LUMO energy levels as well as the bandgap of synthesized CPs, owing to the HOMO and LUMO energy levels being centered on the donor and acceptor moieties, respectively. ${ }^{8}$ For example, isoindigo-based low bandgap polymers, containing thiophene as a donor moiety (PT-ID1), were synthesized and the isoindigo monomer was branched with a 2octyldodecyl side chain to improve the solubility. ${ }^{9}$ The HOMO and LUMO energy levels of PT-ID1 were -5.49 and $-3.91 \mathrm{eV}$, respectively. A photovoltaic device with $\mathrm{PT}-\mathrm{ID} 1 / \mathrm{PC}_{71} \mathrm{BM}$ in a $1: 2$ ratio as the active layer $(70 \mathrm{~nm})$ gave an open circuit voltage $\left(V_{\mathrm{oc}}\right)$ value of $0.87 \mathrm{~V}$, a fill factor $(\mathrm{FF})$ of $60 \%$, and a short circuit current $\left(J_{\mathrm{sc}}\right)$ value of $1.76 \mathrm{~mA} \mathrm{~cm}^{-2}$, resulting in a power conversion efficiency (PCE) value of $0.92 \% .^{9}$ The same polymer structure on the application of OFETs showed a hole-mobility 
$\left(\mu_{\mathrm{h}}\right)$ of $0.019 \mathrm{~cm}^{2} \mathrm{~V}^{-1} \mathrm{~s}^{-1}$, but has a HOMO/LUMO level of $-5.8 /$ $-3.8 \mathrm{eV} .^{\mathbf{1 0 , 1 1}}$

Similarly, an alkylated DPP/thiophene based CP (PDPP3T) showed the onset of optical absorption at $1.30 \mathrm{eV}$ as a small band-gap polymer; its HOMO/LUMO levels were found to be -5.17 and $-3.61 \mathrm{eV}$. The optimized cells provided a PCE value of $4.7 \%$ and gave $\mu_{\mathrm{h}}=0.05 \mathrm{~cm}^{2} \mathrm{~V}^{-1} \mathrm{~s}^{-1}$ and $\mu_{\mathrm{e}}=0.008 \mathrm{~cm}^{2} \mathrm{~V}^{-1}$ $\mathrm{s}^{-1} \cdot{ }^{12}$ A PCE of $6.71 \%$ was recorded for PDPP3T by using the optimal composition of ternary solvent. ${ }^{13}$ Moreover, Leclerc et al. investigated the alternative combination between ID and DPPDT structure moiety-based CPs under Suzuki coupling conditions. This polymer showed HOMO/LUMO levels at -5.3 / $-4.0 \mathrm{eV}$ with a $1.3 \mathrm{eV}$ bandgap. After annealing at $200{ }^{\circ} \mathrm{C}, \mathrm{ID} /$ DPPDT based CP demonstrated an electron mobility of $1.6 \times$ $10^{-4} \mathrm{~cm}^{2} \mathrm{~V}^{-1} \mathrm{~s}^{-1} .^{14}$ In parallel, random copolymers with different molar ratios of DPP to isoindigo $(\mathbf{D P P} /$ isoindigo $=0.3 \mathrm{l}$ $0.7 ; 0.5 / 0.5 ; 0.7 / 0.3)$ with thiophene were synthesized and offered moderate properties between PT-ID1 and PDPP3T. The equal amounts of DPP and isoindigo in the copolymer absorbed a wide range of the solar spectrum from 600 to $900 \mathrm{~nm}$ with a low HOMO level, which is essential for high performance PSCs. These classes of random polymers have bandgaps in the range from 1.38 to $1.46 \mathrm{eV}$ and have semi-crystalline structure characteristics, which may facilitate the hole transport affording high $J_{\mathrm{sc}}=13.52 \mathrm{~mA} \mathrm{~cm}{ }^{-2}$ as well as high PCE, up to $6 \% .^{15}$ The hole mobility of the $0.5 / 0.5$ random copolymer is $0.102 \mathrm{~cm}^{2}$ $\mathrm{V}^{-1} \mathrm{~S}^{-1}$, which is higher than the corresponding alternative. ${ }^{15}$ All the previous CPs contain alkyl side chains for solubility.

On the other hand, the thermolabile tert-butoxy carbonyl (Boc) protecting group is a convenient group for protecting indigo and/or DPP imide $\mathrm{N}-\mathrm{H}$ function during the coupling reactions. These groups can be removed by heat treatment to recover the $\mathrm{N}-\mathrm{H}$ group when desired. The story of Boc-indigo and Boc-DPP started in the $1990 \mathrm{~s},{ }^{\mathbf{1 6}, 17}$ but in the field of organic electronics, the Boc group has made a small contribution and has been employed to allow solution processing. ${ }^{18}$ Bocindigo/fluorine based CP was synthesized and underwent a clean deprotection reaction and showed promising physical properties. ${ }^{19}$ To the best of our knowledge, organic macromolecule materials, such as CPs and small molecules based on Bocisoindigo (Boc-ID), were rarely released. ${ }^{20}$

Besides our interest in CP synthesis and characterization, ${ }^{21-24}$ recently, we have synthesized several novel organic materials based on isoindigo and achieved PCE $=1.6$ up to $3.2 \% .^{25,26}$

In this work, we introduce Boc-ID and Doc-DPP along the backbone structure of a new series of random CPs based on octyldodecyl-alkylated ID and dithienyl-DPP (DTDPP). NProtected electron deficient monomers participate in a small molar ratio on the alternative condensation reaction of alkylated ID and/or DPP with thiophene under Stille coupling polymerization conditions. The new random CPs are designed to exhibit high crystalline structure after the thermal deprotection of Boc and release of the $\mathrm{N}-\mathrm{H}$ function, and help to form $\mathrm{H}$ bonding, which is important for long range ordering in the solid state. The formation of $\mathrm{H}$ bond interactions between polymer chains has been investigated, and their impact on the optical and electrochemical properties has been studied.

\section{Experimental}

\section{Synthetic details}

Co-monomers, (E)-6,6'-dibromo-1,1-bis(2-octyldodecyl)-(3,3'biindolinylid-ene)-2,2'-dione (1) 2,5-bis(2-octyldodecyl)-3,6-di(5bromothien-2-yl)pyrrolo[3,4-c]pyrrole-1,4-(2H,5H)-dione (3) and 2,5-bis(tert-butyloxycarbonyl)-3,6-di(5-bromothien-2-yl)pyrrolo $[3,4-c]$ pyrrole-1,4- $(2 H, 5 H)$-dione $(4)$ were synthesized as per the published literature. ${ }^{1-3}$

1,1-Bis(tert-butyloxycarbonyl)-(3,3'-biindolinylid-ene)-2,2' dione (Boc ID) (2). A solution of $(E)-6,6^{\prime}$-dibromo- $1 H, 1^{\prime} H-\left[3,3^{\prime}\right]$ biindolylidene-2,2'-dione (1.00 g, $2.40 \mathrm{mmol})$ and a catalytic amount of 4-(dimethylamino)pyridine (DMAP) in dry THF (100 $\mathrm{mL}$ ) was stirred at room temperature under argon atmosphere. After $20 \mathrm{~min}$, di-tert-butyl dicarbonate $\left(\mathrm{Boc}_{2} \mathrm{O}\right)(1.60 \mathrm{~g}, 7.10 \mathrm{mmol})$ was added dropwise over $30 \mathrm{~min}$. The solution was stirred at $35^{\circ} \mathrm{C}$ overnight, and then the solvent and excess of $\mathrm{Boc}_{2} \mathrm{O}$ were removed under reduced pressure at $45{ }^{\circ} \mathrm{C}$ to give $2(1.34 \mathrm{~g}$, yield: $90 \%)$ as a bright red solid. ${ }^{1} \mathrm{H} \mathrm{NMR}\left(\mathrm{CDCl}_{3}, 400 \mathrm{MHz}\right), \delta(\mathrm{ppm}): 8.67(\mathrm{~d}, J=$ $8.4 \mathrm{~Hz}, 2 \mathrm{H}), 7.98(\mathrm{~d}, J=7.16 \mathrm{~Hz}, 2 \mathrm{H}), 7.22\left(\mathrm{dd}, J_{1}=8.5 \mathrm{~Hz}, J_{2}=\right.$ $1.9 \mathrm{~Hz}, 2 \mathrm{H}), 6.81$ (d, 2H), 1.60 (s, $18 \mathrm{H}, \mathrm{Boc}-\mathrm{H}) .{ }^{13} \mathrm{C} \mathrm{NMR}\left(\mathrm{CDCl}_{3}\right.$, $100 \mathrm{MHz}), \delta$ (ppm): 165.33, 148.33, 141.88, 131.37, 130.14, 127.26, 125.49, 120.42, 117.85, 85.50, 30.28, 28.06. Elemental analysis: found: C, 50.12; H, 3.91; Br, 25.63; N, 4.50; O, 15.32\%. Calc. for $\mathrm{C}_{26} \mathrm{H}_{24} \mathrm{Br}_{2} \mathrm{~N}_{2} \mathrm{O}_{6}$ : C, 50.34; H, 3.90; Br, 25.76; N, 4.52; O, $15.48 \%$.

\section{General procedures for Pd catalyzed Stille coupling arylation for the synthesis of the new polymers}

Under highly dry conditions, a mixture of 5-bis(tributylstannyl) thiophene (5) (0.66 g, $1.00 \mathrm{mmol})$, the desired alkylated dibromo-derivative of ID/DPP materials ( 1 and/or 3 ) ( $0.8 \mathrm{mmol}$ ), the desired Boc-derivative of ID/DPP materials (2 and/or 4) (0.2 $\mathrm{mmol})$ and $\mathrm{Pd}\left(\mathrm{PPh}_{3}\right)_{4}(0.058 \mathrm{~g}, 0.05 \mathrm{mmol})$ in dry DMF $(20 \mathrm{~mL})$ was degassed with nitrogen for $20 \mathrm{~min}$ then heated under reflux for $24-48 \mathrm{~h}$ at a temperature of $120^{\circ} \mathrm{C}$. The reaction mixture was allowed to return to room temperature and then poured into methanol. The crude polymer was collected by filtration and washed repeatedly with methanol. The residual solid was loaded into an extraction thimble and washed with methanol $(24 \mathrm{~h})$ followed by acetone $(24 \mathrm{~h})$.

P(ODIDT-BID) dark violet color. ${ }^{1} \mathrm{H}$ NMR $\left(\mathrm{CDCl}_{3}, 400 \mathrm{MHz}\right)$, $\delta$ (ppm): 9.27-8.92 (br, 4H), 7.49-6.48 (br, 10H), 3.81-3.33 (br, 2H), 2.72-2.49 (br, 4H) 2.06-1.78 (br, 22H), 1.58-1.05 (br, 76H), 1.02-0.72 (br, 18H).

P(ODIDT - BDPP) dark violet color. ${ }^{1} \mathrm{H} \mathrm{NMR}\left(\mathrm{CDCl}_{3}, 400\right.$ $\mathrm{MHz}$ ), $\delta$ (ppm): 9.31-8.94 (br, 4H), 7.47-6.51 (br, 10H), 3.89-3.48 (br, 2H), 2.70-2.58 (br, 4H) 2.07-1.81 (br, 22H), 1.50-1.04 (br, 76H), 0.96-0.71 (br, 18H).

P(ODDPPT - BID) dark violet color. ${ }^{1} \mathrm{H}$ NMR $\left(\mathrm{CDCl}_{3}, 400\right.$ $\mathrm{MHz}$ ), $\delta$ (ppm): 9.00-8.92 (br, 4H), 7.55-6.79 (br, 10H), 4.14-3.99 (br, 2H), 2.00-1.95 (br, 4H), 1.82-1.59 (br, 22H), 1.59-1.19 (br, $76 \mathrm{H}), 0.98-0.71$ (br, $18 \mathrm{H})$.

P(ODDPPT - BDPP) dark violet color. ${ }^{1} \mathrm{H}$ NMR $\left(\mathrm{CDCl}_{3}, 400\right.$ $\mathrm{MHz}$ ), $\delta$ (ppm): 9.09-8.76 (br, 4H), 7.40-6.73 (br, 10H), 4.06-3.37 (br, 2H), 2.08-1.84 (br, 4H), 1.73-0.95 (br, 98H), 0.93-0.71 (br, $18 \mathrm{H})$. 


\section{Device fabrication}

The bottom-gate/bottom-contact (BGBC) OFET devices were fabricated using $\mathrm{n}++-\mathrm{Si} / \mathrm{SiO}_{2}(200 \mathrm{~nm})$ substrates. The Au electrodes $(40 \mathrm{~nm})$ for the source and drain were thermally evaporated with a length of $50 \mu \mathrm{m}$ and a width of $1000 \mu \mathrm{m}$ on the $\mathrm{SiO}_{2}$ surface under high vacuum $\left(\sim 10^{-6}\right.$ Torr). The substrates were subjected to cleaning by ultra-sonication in deionized water, acetone, and isopropanol each for $20 \mathrm{~min}$. The cleaned substrates were dried in an oven at $80{ }^{\circ} \mathrm{C}$ for $2 \mathrm{~h}$. The substrates were UV/ozone treated for $20 \mathrm{~min}$ and then transferred into a nitrogen-filled glovebox. The thin films of the random CPs were spin-cast on the substrates with the random CP solutions ( $1 \mathrm{wt} \%$ in chloroform) at $3000 \mathrm{rpm}$ for $30 \mathrm{~s}$. As-prepared films were annealed at $200{ }^{\circ} \mathrm{C}$ for $10 \mathrm{~min}$.

\section{Results and discussion}

\section{Molecular design and synthesis}

Random donor-acceptor polymers based on diketopyrrolopyrrole/ isoindigo-thiophene were selected to be the semiconducting backbones for several reasons, such as the excellent device performance that has been shown in organic electronic devices and the easy functionalization of the nitrogen atom on the isoindigo or diketopyrrolopyrrole units. To ensure high solubility a large number of $t$-Boc and octyldedocyl groups were attached. In previous work, the thermolabile random copolymerization strategy showed good solubility with high stacking order in the annealed solid state but had a possible low impact on the electronic performance. ${ }^{20}$

(E)-6,6'-Dibromo-1,1-bis(2-octyldodecyl)-(3,3'-biindolinylidene)-2, $2^{\prime}$-dione (1) was reported in our previous work (Fig. 1). ${ }^{26}$ In this work, we introduce (E)-6,6'-dibromo-1,1-bis(tert-butyloxycarbonyl)-(3,3'-biindolinylid-ene)-2,2'-dione (Boc ID) (2) by the modification of the reported procedure: ${ }^{27}$ treatment of $(E)-6,6^{\prime}$ dibromo- $1 H, 1^{\prime} H-\left[3,3^{\prime}\right]$ biindolylidene-2,2'-dione with 3 equivalents of tert-butyl dicarbonate $\left(t \mathrm{Boc}_{2} \mathrm{O}\right)$ in tetrahydrofuran (THF) at room temperature resulted in over $80 \%$ pure product. Two precursor comonomers, 2,5-bis(2-octyldodecyl)-3,6-di(5-bromothien-2-yl)pyrrolo[3,4-c]pyrrole-1,4- $(2 H, 5 H)$-dione (3) and 2,5bis(tert-butyloxycarbonyl)-3,6-di(5-bromothien-2-yl)pyrrolo[3,4c]-pyrrole-1,4-(2H,5H)-dione (4), were synthesized as per the published literature, ${ }^{\mathbf{2 8 , 1 8 e}}$ (Fig. 1). Moreover, lithiation of thiophene by $n$-BuLi at $-80{ }^{\circ} \mathrm{C}$ followed by quenching with tributyltinchloride gave the corresponding 2,5-bis(tributylstannyl) thiophene (5). All materials were extracted with organic solvents and highly purified via column chromatography.

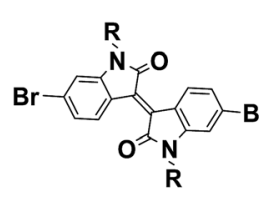

1. $R=$ octyldodecyl2. $R=t-B o c-$

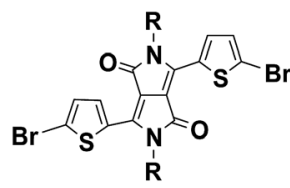

3. $R$ = octyldodecyl4. $R=t-B o c-$

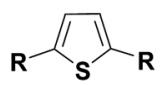

5. $\mathrm{R}=-\mathrm{Sn}(\mathrm{Bu})_{3}$
Fig. 1 Structures of ID and DPP derivatives.

\section{Synthesis of random copolymers}

Based on Stille coupling conditions, the polymerization reactions were done in degassed anhydrous $N, N$-dimethylformamide (DMF) as a solvent in the presence of catalytic amounts of $\mathrm{Pd}\left(\mathrm{PPh}_{3}\right)_{4}$ under $\mathrm{N}_{2}$ atmosphere at $80{ }^{\circ} \mathrm{C}$ using thermal methodology. The alkylated acceptors and $t$-butyloxy carbonyl moieties were mixed with 2,5-bis(tributylstannyl) thiophene (5) in a molar ratio of $0.8: 0.2: 1$, respectively.

New random conjugated polymers were designed to obtain large numbers of octyldodecyl comonomers to insure the solubility for film casting. Polymers P(ODIDT-BID) and P(ODIDT - BDPP) were obtained via Stille coupling reaction, in which comonomers $\mathbf{1}$ and distannyl derivative $\mathbf{5}$ were mixed with Boc monomers 2 or $\mathbf{4}$, respectively, in good yields ( $77 \%$ and $73 \%$ respectively) and acceptable average molecular weights $\left(M_{\mathrm{n}}\right)$ and reasonable polydispersity index (PDI) values (Table 1). Similarly, comonomers 3 and distannyl derivative $\mathbf{5}$ were reacted with Boc monomers $\mathbf{2}$ or $\mathbf{4}$ under Stille coupling conditions in DMF to afford P(ODDPPT-BID) and P(ODDPPT'BDPP) random copolymers in $75 \%$ and $73 \%$ yields, respectively, and showed reasonable molecular weights (Table 1). The synthetic route to the polymers is shown in Scheme 1.

All copolymers showed good solubility at room temperature in most common organic solvents. After purification by Soxhlet extraction with methanol and acetone repeatedly to remove the by-products and the oligomers, all polymer structures were confirmed by ${ }^{1} \mathrm{H}$ NMR and elemental analyses. All the data were inserted with the proposed structures (see the ESI $\dagger$ for the ${ }^{1} \mathrm{H}$ NMR spectra).

\section{Thermal properties}

Under nitrogen atmosphere, thermogravimetric analysis (TGA) was used to investigate the thermal properties of the four new CPs. From TAG analysis, all polymers retained 50\% residual weights when the temperature increased up to $800{ }^{\circ} \mathrm{C}$, except P(ODIDT - BDPP), which lost $60 \%$ of its total weight at $750{ }^{\circ} \mathrm{C}$. All polymers showed two decomposition steps. The thermal decomposition related to isolation of the $t$ Boc function appeared at $T_{\mathrm{d}}$ 98.8-99.8 $\mathrm{wt} \%$ residues in the range of 180$220{ }^{\circ} \mathrm{C}$.

The second thermal decomposition temperatures $\left(T_{\mathrm{d}}, 92-84\right.$ $\mathrm{wt} \%$ residues) were in the range of $388-436{ }^{\circ} \mathrm{C}$, related to the decomposition of the long alkyl chains during heating, ${ }^{29}$ which confirmed the high thermal stability of all polymer products. The thermogravimetric analysis diagrams of the synthesized random copolymers are shown in the ESI (Fig. S1 $\dagger$ ).

To provide the formation of $\mathrm{H}$-bonds after the thermal elimination of the $t$-Boc groups, Fourier transform infrared (FTIR) spectroscopy was used (Fig. S2 $\dagger$ ). In general in the annealed films, a weak band was found at around $3450 \mathrm{~cm}^{-1}$, which was assigned to the lactam structure $\mathrm{N}-\mathrm{H} \cdots \mathrm{O}=\mathrm{C}$ hydrogen bonding of the isoindigo and DPP units. In addition, the stretching vibration band of $\mathrm{C}=\mathrm{O}$ at $\sim 1700 \mathrm{~cm}^{-1}$ disappeared, which clearly confirmed the complete decomposition of $t$-Boc groups, and the lactam moiety $\mathrm{C}=\mathrm{O}$ shifted to slightly smaller wavenumber. 
Table 1 Polymerization ${ }^{a}$ results and thermal properties of copolymers

\begin{tabular}{|c|c|c|c|c|}
\hline Polymer & $M_{\mathrm{n}}^{b}\left(\mathrm{~kg} \mathrm{~mol}^{-1}\right)$ & PDI $\left(M_{\mathrm{w}} / M_{\mathrm{n}}\right)^{b}$ & Yield $^{c}(\%)$ & $T_{\mathrm{d}}{ }^{d}\left({ }^{\circ} \mathrm{C}\right)$ \\
\hline P(ODIDT· BID) & 20.2 & 1.81 & 77.0 & 338.4 \\
\hline P(ODIDT · BDPP) & 19.7 & 1.77 & 73.0 & 390.3 \\
\hline P(ODDPPT · BDPP $)$ & 17.2 & 1.71 & 73.0 & 391.9 \\
\hline
\end{tabular}

${ }^{a}$ All polymerizations were carried out using the Stille cross-coupling method. ${ }^{b}$ Calculated from GPC (eluent, $\mathrm{CHCl}_{3} ; 30{ }^{\circ} \mathrm{C} ;$ polystyrene standards). ${ }^{c}$ Based on the weight of pure polymer obtained. ${ }^{d}$ Determined by DSC under nitrogen atmosphere at a heating rate of $10^{\circ} \mathrm{C}$ min ${ }^{-1}$.

\section{Optical properties}

Fig. 2 shows the solution and film absorption spectra of the new polymers. In dilute solutions of polymers in chloroform,
P(ODDPPT $\cdot$ BID $)$ and $\mathbf{P ( O D D P P T} \cdot$ BDPP) offered one absorption band, which indicates the intermolecular charge transfer (ICT) between donor and acceptor units, with maxima at 612 and $616 \mathrm{~nm}$, respectively.

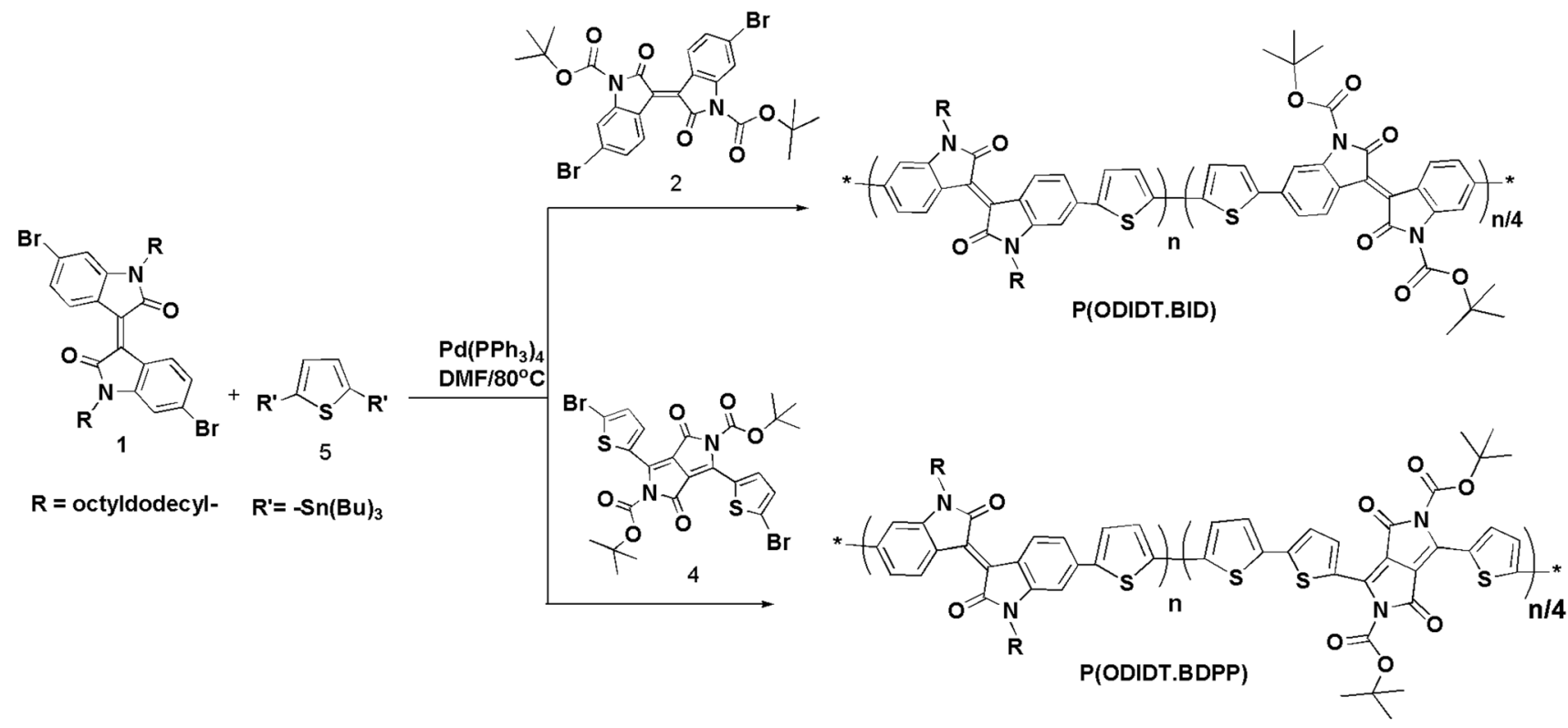

$\mathrm{Br}$<smiles>[R]c1ccc([R])s1</smiles>

$R=$ octyldodecyl- $\quad R^{\prime}=-\operatorname{Sn}(B u)_{3}$
$\mathrm{Pd}\left(\mathrm{PPh}_{3}\right)_{4}$

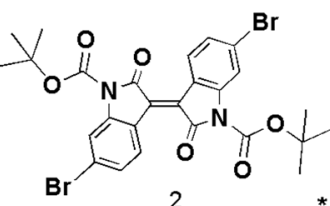

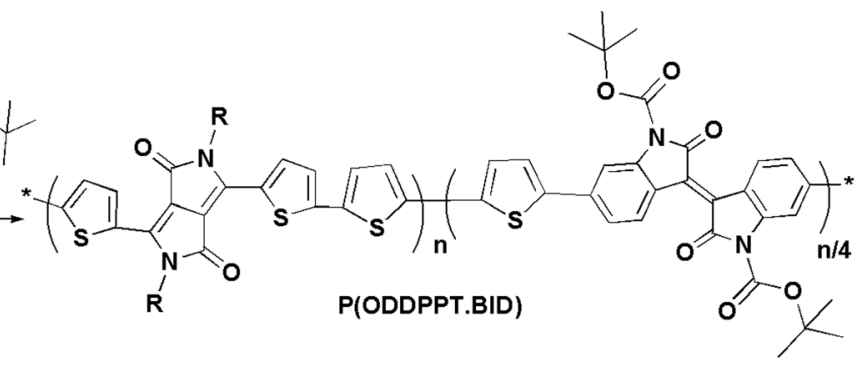

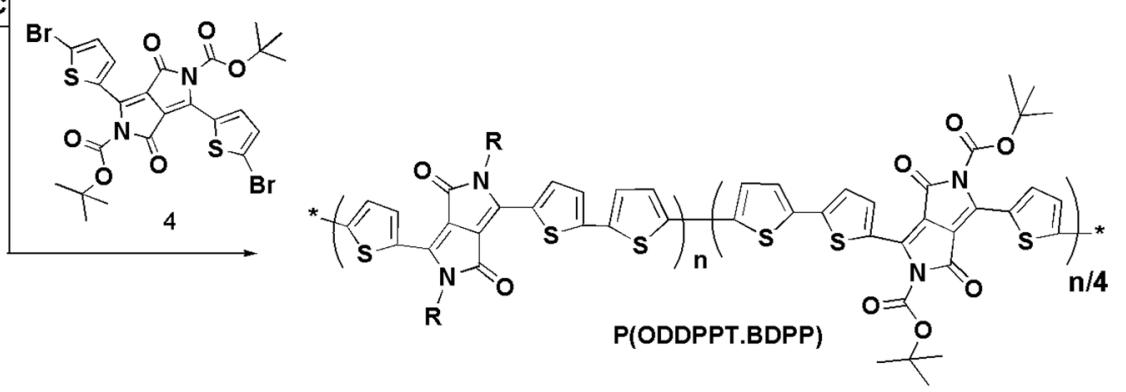



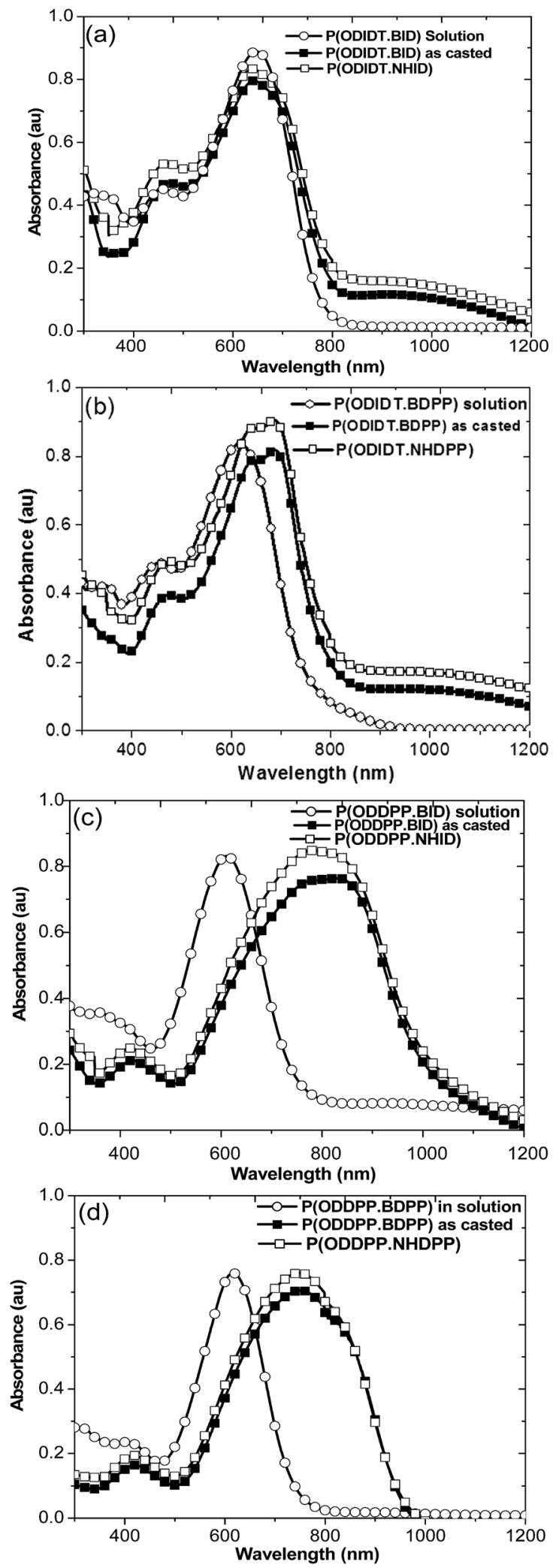

Fig. 2 UV-vis spectra for random copolymers solutions, as casted films and after thermal annealing.

However, P(ODIDT-BID) and P(ODIDT - BDPP) showed two major absorption bands in dilute solutions, the shorter wavelength absorption bands at 451 and $454 \mathrm{~nm}$ for P(ODIDT-BID) and P(ODIDT $\cdot$ BDPP), respectively, are indicated from the $\pi-\pi^{*}$ transition and the longer absorption bands at wavelength $646 \mathrm{~nm}$ and $620 \mathrm{~nm}$, respectively, representing the ICT at the donor-acceptor composition.

In solid films, polymers containing ODDPP showed broader absorbance than ODID-based polymers, which reflects the high $\pi$-stacking ordering in the case of ODDPP based polymers. Corresponding to the absorption edges, polymers based on ODID represent a slight red shift in solid state film compared to in dilute solutions. $\mathbf{P}\left(\right.$ ODIDT-BID) showed $\lambda_{\text {onset }}=823 \mathrm{~nm}$ in film and $\lambda_{\text {onset }}=796 \mathrm{~nm}$ in solution. Similarly, P(ODIDT·BDPP) exhibits absorption edges at $850 \mathrm{~nm}$ in film and $792 \mathrm{~nm}$ in solution. In contrast, random CPs based on ODDPP offer long range red shift and broadness compared to their corresponding absorptions in solution, reflecting the increasing interchain interaction and ordering along the polymer backbones as well as the extended $\pi$-conjugation length in the solid state. The onset absorptions of $\mathbf{P ( O D D P P T \cdot B I D )}$ and P(ODDPPT·BDPP) are $1036 \mathrm{~nm}$ and $980 \mathrm{~nm}$, respectively, more red shifted by approximately $200 \mathrm{~nm}$ than the absorptions edges in solution. The optical bandgaps of all polymers, which were calculated from $\lambda_{\text {onset }}$ in the solid state $\left[E_{\mathrm{g}}^{\mathrm{op}}(\mathrm{eV})=1240 / \lambda_{\text {onset }}(\mathrm{nm})\right]$, are $1.51,1.46$, 1.20 and $1.26 \mathrm{eV}$ for P(ODIDT-BID), P(ODIDT $\cdot$ BDPP), P(ODDPPT $\cdot$ BID) and P(ODDPPT $\cdot$ BDPP), respectively (Table 2). The new random CPs possess lower optical band gaps and broader absorption windows than their corresponding CPs not containing N-block $t$ Boc-acceptors along their backbone structures. ${ }^{9,15}$ Interestingly, in the as-cast films, P(ODDPPT-BID) and P(ODDPPT - BDPP) offered second short absorption bands, which indicate the $\pi-\pi^{*}$ transition, at $423 \mathrm{~nm}$ and $420 \mathrm{~nm}$, respectively.

Furthermore, after annealing polymer films up to $220{ }^{\circ} \mathrm{C}$ to ensure the recovery of the $\mathrm{N}-\mathrm{H}$ function and liberation of the $t$ Boc group, all polymers showed two major absorption bands and induced a slight red shift, which indicates a great increase of long range ordering and the $\pi$-stacking orientation of the semi-crystalline polymer structures.

\section{Electrochemical properties}

The electrochemical properties of the polymers were explored by cyclic voltammetry (CV). The cyclic voltammograms of the

Table 2 Optical properties of the four copolymers

\begin{tabular}{|c|c|c|c|c|}
\hline \multirow[b]{3}{*}{ Polymer } & \multicolumn{4}{|c|}{ UV-vis absorption } \\
\hline & \multirow{2}{*}{$\begin{array}{l}\text { Solution } \\
\lambda_{\max } \\
(\mathrm{nm})\end{array}$} & \multicolumn{3}{|c|}{ In film } \\
\hline & & $\begin{array}{l}\lambda_{\max } \\
(\mathrm{nm})\end{array}$ & $\begin{array}{l}\lambda_{\text {onset }} \\
(\mathrm{nm})\end{array}$ & $\begin{array}{l}E_{\mathrm{g}}^{\mathrm{op}} \\
(\mathrm{eV})\end{array}$ \\
\hline P(ODIDT-BID) & 641 & 641 & 791 & 1.57 \\
\hline P(ODIDT · NHID $)$ & & 641 & 801 & 1.55 \\
\hline P(ODIDT·BDPP) & 617 & 680 & 801 & 1.55 \\
\hline P(ODIDT $\cdot$ NHDPP $)$ & & 684 & 807 & 1.54 \\
\hline P(ODDPPT $\cdot$ BID $)$ & 614 & 839 & 1019 & 1.22 \\
\hline P(ODDPPT · NHID $)$ & & 782 & 1038 & 1.20 \\
\hline P(ODDPPT· BDPP) & 618 & 751 & 955 & 1.30 \\
\hline P(ODDPPT $\cdot$ NHDPP $)$ & & 744 & 955 & 1.30 \\
\hline
\end{tabular}


P(ODIDT-BID), $\quad$ P(ODIDT - BDPP),$\quad$ P(ODDPPT - BID $) \quad$ and P(ODDPPT $\cdot$ BDPP $)$ films are shown in Fig. 3.

The HOMO and LUMO energy levels of the polymers were calculated according to the equations: $E_{\text {Номо }}=-\left(E_{\text {ох }}+4.71\right) \mathrm{eV}$ and $E_{\mathrm{LUMO}}=-\left(E_{\mathrm{red}}+4.71\right) \mathrm{eV}$, where $E_{\mathrm{ox}}$ and $E_{\text {red }}$ are the onset oxidation and reduction potentials, respectively, of the polymers vs. $\mathrm{Ag} / \mathrm{Ag} \mathrm{Cl}$ (saturated $\mathrm{KCl}$ ) as a reference electrode. The HOMO energy levels moved gradually deeper in the order [P(ODIDT-BID) $>$ P(ODIDT $\cdot$ BDPP $)>\mathbf{P}($ ODDPPT $\cdot$ BID $)>\mathbf{P}($ ODDPPT BDPP $)]$ and showed $-5.44,-5.65,-5.68$ and $-5.69 \mathrm{eV}$, respectively. However, there are contrasts in the LUMO energy levels of the polymers. The random CPs based on the same structure of electron accepting units offered higher LUMO energy levels than the other containing a mixed (ID/DPP) backbone structure. The LUMO energy level of P(ODDPPT - BDPP) was the highest at $-3.89 \mathrm{eV}$, thus P(ODIDT-BID) and P(ODIDT $\cdot$ BDPP) exhibited LUMO energy levels at -3.97 and $-4.13 \mathrm{eV}$, respectively. However, the LUMO energy level of P(ODDPPT $\cdot$ BID) was the lowest at $-4.17 \mathrm{eV}$. Moreover, the electrochemical bandgaps $\left(E_{\mathrm{g}}\right.$ $\left.=E_{\mathrm{LUMO}}-E_{\mathrm{HOMO}}\right)$ of $\mathbf{P}($ ODIDT-BID $), \mathbf{P}($ ODIDT $\cdot$ BDPP $), \mathbf{P}($ ODDPPT $\cdot$ BID) and P(ODDPPT BDPP) were 1.47, 1.52, 1.51 and $1.80 \mathrm{eV}$, respectively.
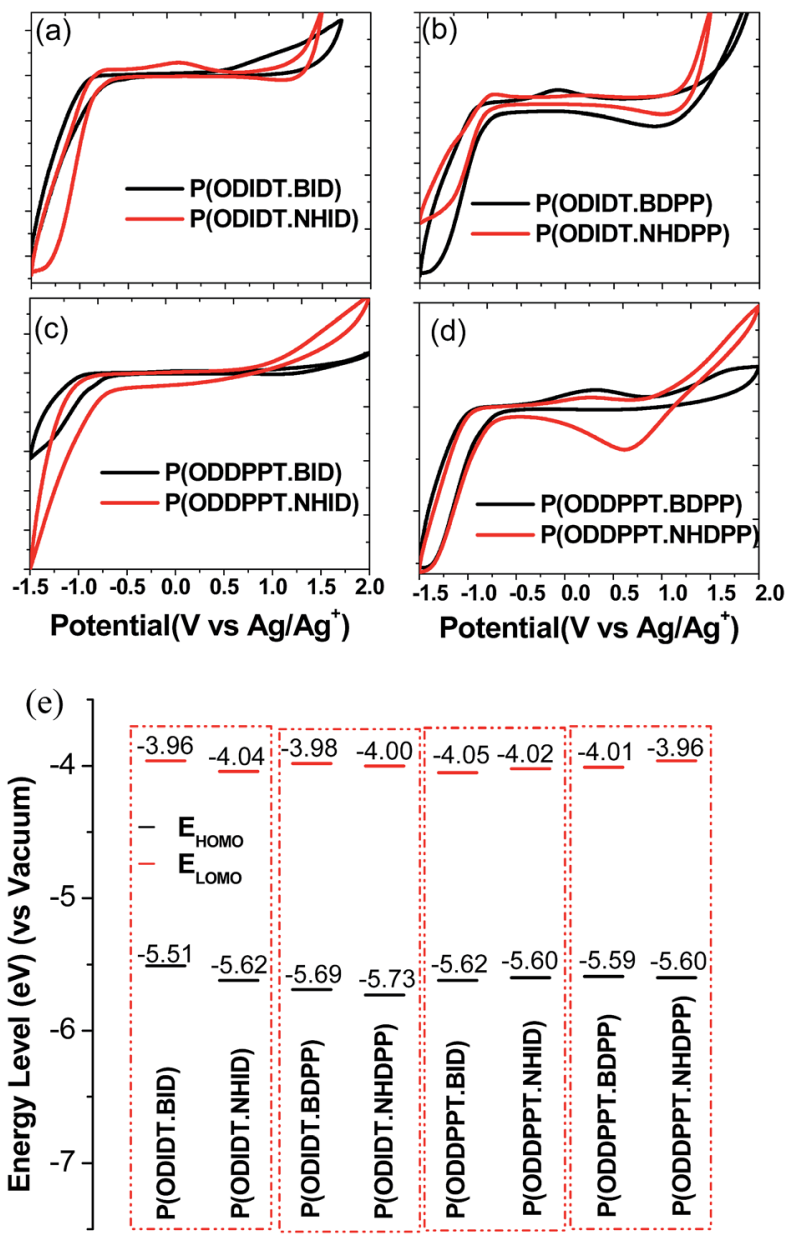

Fig. 3 (a-d) Cyclic voltammograms of all annealed polymer thin films measured in a $0.1 \mathrm{M}$ solution of $\mathrm{TBAPF}_{6}$ in acetonitrile at a scan rate of $50 \mathrm{mV} \mathrm{s}^{-1}$ as film; (e) HOMO and LUMO energy levels diagram.
In the case of decarboxylated polymers ( $\mathrm{NH}$-forms), the improvement of $\pi-\pi$ packing did not show a significant change to the HOMO and LUMO energy levels. However, in the case of P(ODIDT-NHID), it showed a deeper HOMO level at $-5.62 \mathrm{eV}$ than its corresponding $\mathbf{P}$ (ODIDT-BID) polymer.

In many aspects, the new synthesized random CPs showed low band-gaps closely matched the ideal low band gaps of the polymers used for organic electronic applications.

\section{Crystalline structure of polymers}

Charge carrier transport strongly depends on microstructure in CPs. To explain that, the X-ray diffractometry (XRD) measurements of the as-spun films and the films annealed at $200{ }^{\circ} \mathrm{C}$ are shown in Fig. 4. The as-spun films of P(ODDPPT - BID) and P(ODDPPT $\cdot$ BDPP) showed diffraction peaks at $2 \theta=6.65^{\circ}$ and $6.51^{\circ}$, which corresponded to $d$-spacing of $13.3 \AA$ and $13.6 \AA$, respectively. However, P(ODIDT-BID) and P(ODIDT-BDPP) exhibited week arrangement of diffraction peaks at $2 \theta=4.00^{\circ}$ and $3.87^{\circ}$, proportional to $d$-spacing of $22.1 \AA$ and $22.8 \AA$, respectively, considered to reflect the inter-lamellar distance induced by octyldodecyl chains (Fig. 4a). After annealing at $200{ }^{\circ} \mathrm{C}$ for $10 \mathrm{~min}$ to remove the $t \mathrm{Boc}$ function, the molecular ordering was improved by thermal annealing as well as the formation of $\mathrm{H}$ bonding across polymer chains. As a result, two new sharp and intensive diffraction peaks were found after the annealing process. The diffraction peaks at $2 \theta=8.52^{\circ}, 8.56^{\circ}$, $8.74^{\circ}$ and $8.67^{\circ}$, for $\mathbf{P}$ (ODIDT-BID), P(ODIDT $\cdot$ BDPP), P(ODDPPT - BID) and P(ODDPPT - BDPP) films, respectively, considering the $d$-spacing of 10.0-10.4 $\AA$ confirming much stacking between the alkyl chains, owing to the formation of $\mathrm{H}$ bonding between polymer chain upon the removal by thermocleavage of the $t$ Boc function during heating, which resulted in the shortening of the interlayer distance.

The other diffraction peaks at $2 \theta=17.28^{\circ}, 17.32^{\circ}, 17.98^{\circ}$ and $17.39^{\circ}$ for $\mathbf{P}($ ODIDT-BID $), \mathbf{P}($ ODIDT $\cdot$ BDPP $), \mathbf{P}($ ODDPPT $\cdot$ BID $)$ and P(ODDPPT - BDPP) films, respectively, corresponding to $d$ spacing of 5.0-5.2 $\AA$, indicating that it adopted the highest degree of $\pi-\pi$ stacking, suggested that these peaks did not only originate from crystallites formed by a combination of edge-toedge and face-to-face packing but also from localized aggregation. These localized aggregates could readily form in synthesized polymers because of the enhanced backbone planarity and the incorporated successive $\mathrm{H}$-bonding, which exhibit greatly reduced steric hindrance compared with $t$ Boc units.

\section{Field-effect properties of polymers}

To investigate the charge transport properties of the synthesized random CPs, we fabricated bottom-gate and top-contact (BGTC) OFETs with them. ${ }^{30,31}$ Fig. $5 \mathrm{~b}$ presents the transfer curves of the OFETs with the random CPs. There are no field-effect characteristics in the devices with $\mathbf{P}($ ODIDT-BID) and $\mathbf{P}($ ODIDT $\cdot$ BDPP), while the $\mathbf{P}($ ODDPPT $\cdot$ BID $)$ and $\mathbf{P}($ ODDPPT $\cdot$ BDPP) show fine field-effect characteristics. The field-effect mobilities were extracted from the saturation region in the transfer curves by using the following equation: $I_{\mathrm{DS}}=(W / 2 L) C \mu\left(V_{\mathrm{GS}}-V_{\mathrm{T}}\right)^{2}$ (Table 3), where $W, L, C, \mu, I_{\mathrm{DS}}, V_{\mathrm{GS}}$, and $V_{\mathrm{T}}$ are channel width, 

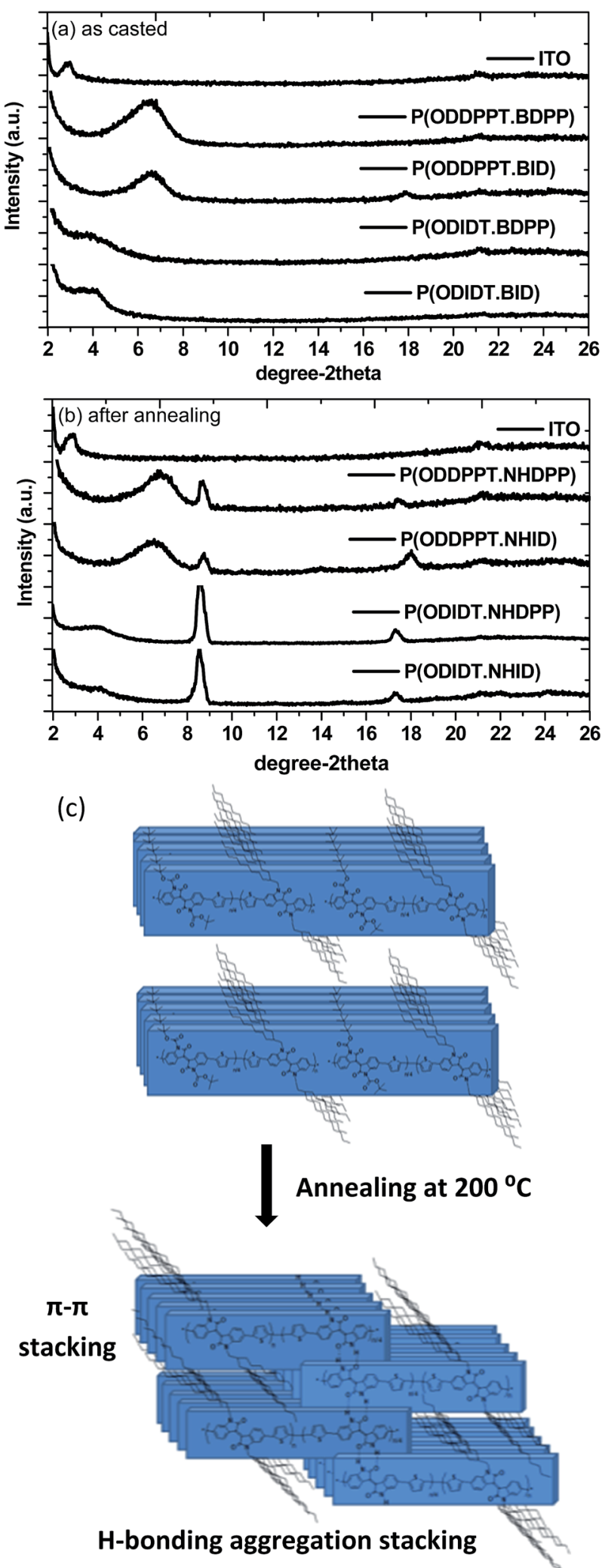

Fig. 4 XRD diagrams obtained from all polymer thin films on ITO substrate (a) as-spun thin film (r.t.) (b) annealed at $220^{\circ} \mathrm{C}$ for $30 \mathrm{~min}$, and (c) schematic representations of $\pi-\pi$ stacking P(ODIDT-BID) as cast and after annealing.

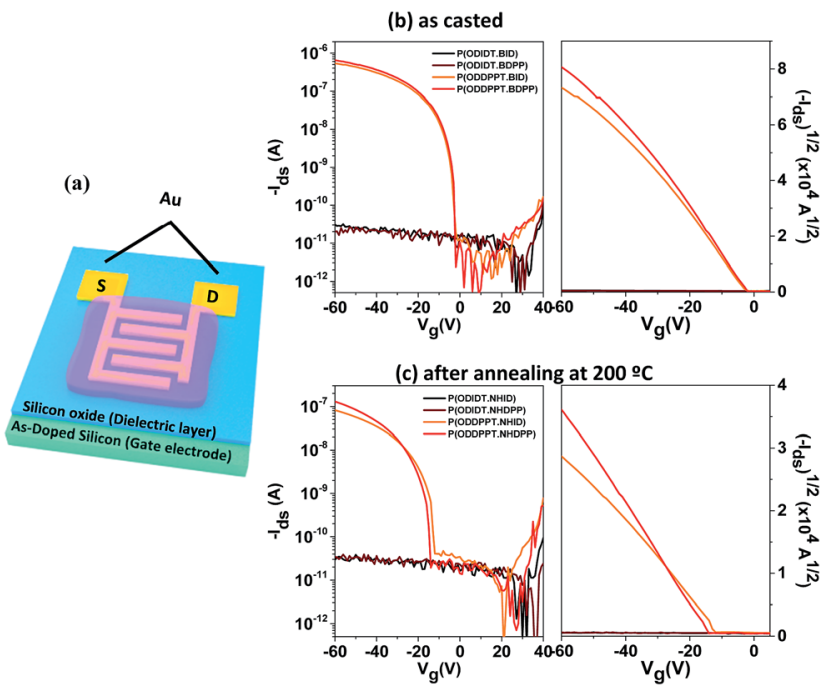

Fig. 5 Transistor characteristics of synthesized new polymers: (a) illustration of OFET configuration. (b) and (c) Transfer curves of devices with P(ODIDT-BID), P(ODIDT-BDPP), P(ODDPPT·BID) and P(ODDPPT·BDPP) (b) as casted and (c) after annealing treatment at $200^{\circ} \mathrm{C}$.

channel length, gate dielectric capacitance per unit area, charge carrier mobility, drain-source current, gate-source voltage, and the threshold voltage, respectively.

As summarized in Table 3, as-spun films of P(ODIDT-BID) and $\mathbf{P}($ ODIDT $\cdot$ BDPP $)$ exhibited relatively lower hole mobilities of $2.26 \times 10^{-8} \mathrm{~cm}^{2} \mathrm{~V}^{-1} \mathrm{~s}^{-1}$ and $6.68 \times 10^{-8} \mathrm{~cm}^{2} \mathrm{~V}^{-1} \mathrm{~s}^{-1}$, respectively, while higher hole mobilities were obtained in the as-spun films of P(ODIDT-BID) and P(ODIDT $\cdot$ BDPP) $(1.17 \times$ $10^{-3} \mathrm{~cm}^{2} \mathrm{~V}^{-1} \mathrm{~s}^{-1}$ and $1.41 \times 10^{-3} \mathrm{~cm}^{2} \mathrm{~V}^{-1} \mathrm{~s}^{-1}$, respectively); these results are in good agreement with the observations from the XRD analysis. However, after the films were annealed at $200{ }^{\circ} \mathrm{C}$, poor performance with relatively lower $\mu$ and negativelyshifted $V_{\mathrm{T}}$ were observed, which can be ascribed to the interruption of charge carrier injection owing to the morphology change during thermal annealing.

\section{Surface morphologies}

Therefore, we examined the surface morphologies of the films before and after annealing with tapping mode atomic force microscopy (AFM).

Table 3 Summary of transistor characteristics of newly synthesized random CPs

\begin{tabular}{|c|c|c|c|}
\hline Polymer & $\begin{array}{l}\text { Mobility } \\
\left(\mathrm{cm}^{2} \mathrm{~V}^{-1} \mathrm{~s}^{-1}\right)\end{array}$ & On/off ratio & $\begin{array}{l}V_{\mathrm{T}} \\
(\mathrm{V})\end{array}$ \\
\hline P(ODIDT· BID $)$ & - & - & - \\
\hline P(ODIDT · NHID $)$ & - & - & - \\
\hline P(ODIDT · BDPP) & - & - & - \\
\hline P(ODIDT· NHDPP $)$ & - & - & - \\
\hline P(ODDPPT $\cdot$ BID $)$ & $1.17 \times 10^{-3}$ & $4.24 \times 10^{4}$ & -2.6 \\
\hline P(ODDPPT $\cdot$ NHID $)$ & $2.07 \times 10^{-4}$ & $2.02 \times 10^{3}$ & -10.1 \\
\hline P(ODDPPT $\cdot$ BDPP $)$ & $1.41 \times 10^{-3}$ & $1.01 \times 10^{5}$ & -2.3 \\
\hline P(ODDPPT $\cdot$ NHDPP $)$ & $3.91 \times 10^{-4}$ & $6.80 \times 10^{3}$ & -13.9 \\
\hline
\end{tabular}


As shown in Fig. 6, the pristine films of $\mathbf{P}($ ODIDT-BID) and P(ODIDT - BDPP) showed smooth surface morphology, but that did not reveal any structural features. However, densely-packed large domains but rough morphologies were observed in $\mathbf{P}($ ODDPPT $\cdot$ BID $)$ and $\mathbf{P}$ (ODDPPT - BDPP) films owing to relatively strong inter-lamellar stacking. After annealing, it no significant change was observed in the morphology of the films of P(ODIDT-NHID) and P(ODIDT-NHDPP), compared to those of $\mathbf{P}$ (ODIDT-BID) and $\mathbf{P}$ (ODIDT- BDPP) films. Note that $\mathbf{P}($ ODDPPT $\cdot$ NHID $)$ and $\mathbf{P}($ ODDPPT $\cdot$ NHDPP $)$ films exhibited (a) as casted films P(ODIDT.BID)

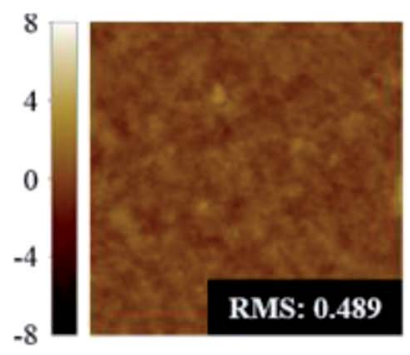

P(ODIDT.BDPP)

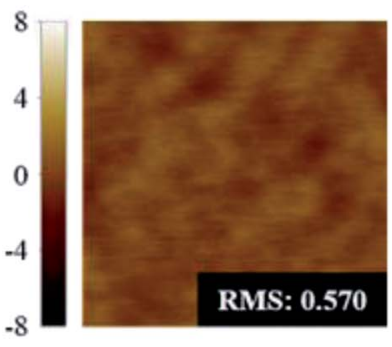

P(ODDPPT.BID)

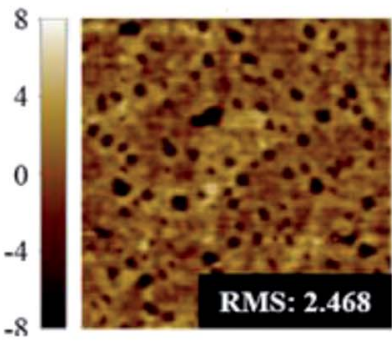

P(ODDPPT.BDPP)

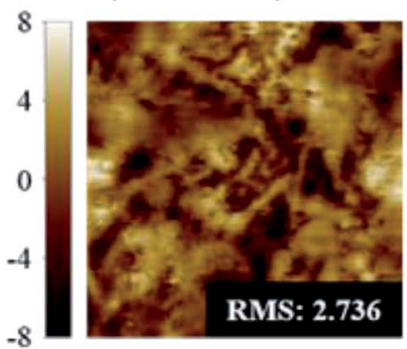

(b) after annealing at 200 C P(ODIDT.NHID)

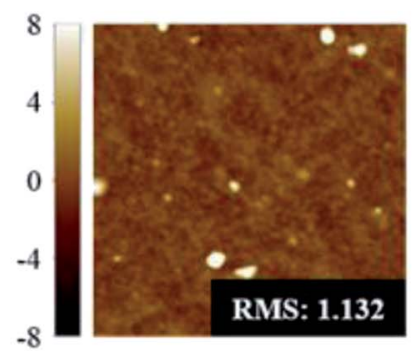

P(ODIDT.NHDPP)

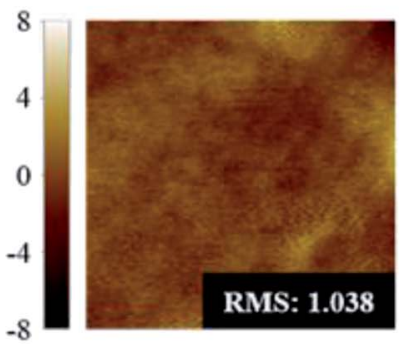

P(ODDPPT.NHID)

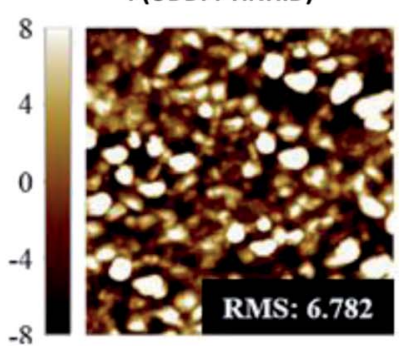

P(ODDPPT.NHDPP)

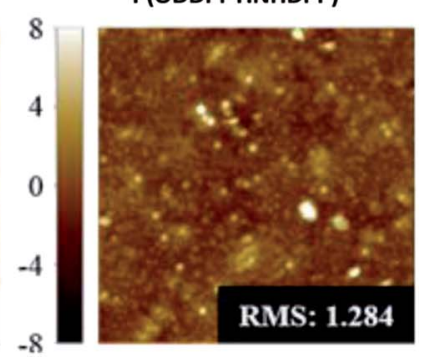

Fig. 6 Tapping-mode atomic force microscopy images of synthesized new polymers: (a) as casted films and (b) after annealing treatment at $200^{\circ} \mathrm{C}$. smaller aggregates or domains in the surface morphology. These phenomenon agreed with the XRD results, whereby aggregated crystallites were formed by $\mathrm{H}$ bonding across polymer chains. Removing $t$ Boc-units by thermal annealing results in molecular ordering within small aggregates having disconnected morphology. This kind of molecular ordering leads to difficulties in charge carrier mobility in OFET devices, which require lateral transfers, but this may have better performance in vertical transfer or in other future devices.

\section{Conclusions}

Narrow bandgap random co-polymeric semiconductors, comprising alkyl substituted diketopyrrolopyrrole (DPP) and isoindigo (ID) and tert-butoxycarbonyl ( $t$-BOC)-protected DPP/ ID, were synthesized and used in organic field-effect transistors (OFETs). The polymer films were prepared by solution deposition and thermal annealing of precursors featuring thermally labile $t$-BOC groups. The effects of the thermal cleavage on the molecular packing structure in the polymer thin films were investigated using thermogravimetric analysis (TGA), UV-vis spectroscopy, and X-ray diffraction (XRD) analysis. By utilizing $t$-BOC thermolysis at $220^{\circ} \mathrm{C}$, the BOC films were directly converted to deprotected films that can potentially possess a hydrogen-bonded network. Finally, we fabricated OFET devices with these random CPs. The trend of field-effect mobility of the as-spun OFET corresponds to that of the XRD data. However, excessive aggregation of the random CP films during thermal annealing results in the performance degradation in the OFET devices.

\section{Acknowledgements}

The research was supported by the Basic Science Research Program though the National Research Foundation (NRF) funded by the Ministry of Science, ICT and Future Planning (NRF2015R1A2A1A01002493); and by the GIST Research Institute (GRI) project through a grant provided by GIST in 2017.

\section{Notes and references}

1 (a) P. Qi, Z. Wang, Z. Liu, S. Yang, Y. Yang, J. Yao, G. Zhang and D. Zhang, Polym. Chem., 2016, 7, 3838; (b) P. Deng and Q. Zhang, Polym. Chem., 2014, 5, 3298; (c) J.-R. Pouliot, B. Sun, M. Leduc, A. Najari, Y. Li and M. Leclerc, Polym. Chem., 2015, 6, 278.

2 R. Stalder, J. Mei, K. R. Graham, L. A. Estrada and J. R. Reynolds, Chem. Mater., 2014, 26, 664.

3 S. Holliday, J. E. Donaghey and I. McCulloch, Chem. Mater., 2014, 26, 647.

4 J.-M. Jiang, M.-C. Yuan, K. Dinakaran, A. Hariharan and K.-H. Wei, J. Mater. Chem. A, 2013, 1, 4415.

5 H.-W. Lin, W.-Y. Lee and W.-C. Chen, J. Mater. Chem., 2012, 22, 2120.

6 Y. N Li, P. Sonar, S. P. Singh, W. J. Zeng and M. S. Soh, J. Mater. Chem., 2011, 21, 10829. 
7 J. Fan, J. D. Yuen, M. F. Wang, J. Seifter, J.-H. Seo, A. R. Mohebbi, D. Zakhidov, A. J. Heeger and F. Wudl, Adv. Mater., 2012, 24, 2186.

8 S. C. Lan, P. A. Yang, M. J. Zhu, C. M. Yu, J. M. Jiang and K. H. Wei, Polym. Chem., 2013, 4, 1132.

9 G. Zhang, Y. Fu, Z. Xie and Q. Zhang, Macromolecules, 2011, 44, 1414.

10 T. Lei, Y. Cao, Y. Fan, C.-J. Liu, S.-C. Yuan and J. Pei, J. Am. Chem. Soc., 2011, 133, 6099.

11 T. Lei, Y. Cao, X. Zhou, Y. Peng, J. Bian and J. Pei, Chem. Mater., 2012, 24, 1762.

12 J. C. Bijleveld, A. P. Zoombelt, S. G. J. Mathijssen, M. M. Wienk, M. Turbiez, D. M. de Leeuw and R. A. J. Janssen, J. Am. Chem. Soc., 2009, 131, 16616.

13 L. Ye, S. Zhang, W. Ma, B. Fan, X. Guo, Y. Huang, H. Ade and J. Hou, Adv. Mater., 2012, 24, 6335.

14 F. Grenier, P. Berrouard, J.-R. Pouliot, H.-R. Tseng, A. J. Heeger and M. Leclerc, Polym. Chem., 2013, 4, 1836.

15 J. W. Jung, F. Liu, T. P. Russell and W. H. Jo, Energy Environ. Sci., 2013, 6, 3301.

16 J. S. Zambounis, Z. Hao and A. Iqbal, Nature, 1997, 388, 131. 17 U. Schaedeli, J. S. Zambounis, A. Iqbal, Z. Hao and H. Dubas, EP $0654711,1993$.

18 (a) C. Lee, Y. Seo and S. Lee, Macromolecules, 2004, 37, 4070; (b) T. L. Chen, J. J.-A. Chen, L. Catane and B. Ma, Org. Electron., 2011, 12, 1126; (c) H. Yanagisawa, J. Mizuguchi, S. Aramaki and Y. Sakai, Jpn. J. Appl. Phys., 2008, 47, 4728; (d) Y. Suna, J. Nishida, Y. Fujisaki and Y. Yamashita, Chem. Lett., 2011, 40, 822; (e) Y. Suna, J. Nishida, Y. Fujisaki and Y. Yamashita, Org. Lett., 2012, 14, 3356; (f) L. Yang, Y. Yu, Y. Gong, J. Li, F. Ge, L. Jiang, F. Gao and Y. Dan, Polym. Chem., 2015, 6, 7005.

19 H. Fukumoto, H. Nakajima, T. Kojima and T. Yamamoto, Materials, 2014, 7, 2030.

20 (a) Z.-H. Guo, N. Ai, C. R. McBroom, T. Yuan, Y.-H. Lin, M. Roders, C. Zhu, A. L. Ayzner, J. Pei and L. Fang, Polym. Chem., 2016, 7, 648; (b) C. Liu, S. Dong, P. Cai, P. Liu,
S. Liu, J. Chen, F. Liu, L. Ying, T. P. Russell, F. Huang and Y. Cao, ACS Appl. Mater. Interfaces, 2015, 7, 9038-9051; (c) J. Lee, A. R. Han, J. Hong, J. H. Seo, J. H. Oh and C. Yang, Adv. Funct. Mater., 2012, 22, 4128; (d) E. Wang, W. Mammo and M. R. Andersson, Adv. Mater., 2014, 26, 1801; (e) L. Dou, J. You, Z. Hong, Z. Xu, G. Li, R. A. Street and Y. Yang, Adv. Mater., 2013, 25, 6642; (f) L. Fang, Y. Zhou, Y.-X. Yao, Y. Diao, W.-Y. Lee, A. L. Appleton, R. Allen, J. Reinspach, S. C. B. Mannsfeld and Z. Bao, Chem. Mater., 2013, 25, 4874.

21 A. A. El-Shehawy, N. I. Abdo, A. A. El-Barbary and J.-S. Lee, Eur. J. Org. Chem., 2011, 25, 4841.

22 N. I. Abdo, A. A. El-Shehawy, A. A. El-Barbary and J.-S. Lee, Eur. J. Org. Chem., 2012, 5540.

23 (a) A. A. El-Shehawy, N. I. Abdo, A. A. El-Barbary and J.-S. Lee, Tetrahedron Lett., 2010, 51, 4526; (b) N. I. Abdo, J. Ku, A. A. ElShehawy, H.-S. Shim, J.-K. Min, A. A. El-Barbary, Y. H. Jang and J.-S. Lee, J. Mater. Chem. A, 2013, 1, 10306.

24 M. Shaker, C. K. Trinh, W. Kim, H. Kim, K. Lee and J.-S. Lee, New J. Chem., 2015, 39, 4957.

25 (a) W. Elsawy, C.-L. Lee, S. Cho, S.-H. Oh, S.-H. Moon, A. Elbarbary and J.-S. Lee, Phys. Chem. Chem. Phys., 2013, 15, 15193; (b) W. Elsawy, H. Kang, K. Yu, A. Elbarbary, K. Lee and J.-S. Lee, J. Polym. Sci., Part A: Polym. Chem., 2014, 52, 2926.

26 M. Shaker, J.-H. Lee, C. K. Trinh, W. Kim, K. Lee and J.-S. Lee, RSC Adv., 2015, 5, 66005.

27 E. D. Glowacki, G. Voss, K. Demirak, M. Havlicek, N. Sünger, A. C. Okur, U. Monkowius, J. Gasiorowski, L. Leonat and N. S. Sariciftci, Chem. Commun., 2013, 49, 6063.

28 Y. Deng, Y. Chen, X. Zhang, H. Tian, C. Bao, D. Yan, Y. Geng and F. Wang, Macromolecules, 2012, 45, 8621.

29 K. Godula and D. Sames, Science, 2006, 312, 67.

30 J. Zaumseil, K. W. Baldwin and J. A. Rogers, J. Appl. Phys., 2003, 93, 6117.

31 B. H. Lee, G. C. Bazan and A. J. Heeger, Adv. Mater., 2016, 28, 57. 